The discussion of these criticisms would lead too far afield; and no further comment on this paper can be so useful as the urgent counsel to the reader of this notice to refer to the original.

Mary Whiton Calkins.

WELLESLEY COLLEGH.

\title{
CLASSIFICATION OF THE SCIENCES.
}

Zur Einteilung der Wissenschaften. C. STumpF. Repr. fr. Abhandl. d. Preuss. Akad. d. Wissenschaften, 1906. Berlin, 1907. Pp. 94.

The conceptions of phenomenon and of psychic function, as outlined in the paper just reviewed, lie at the basis of the classification of the sciences proposed by Stumpf in the second of his contributions to the Abhandlungen of the Prussian Akademie der Wissenschaften. At the outset, and again in conclusion, he pronounces in favor of a classification based, frankly, on several principles. A division proceeding on strictly logical principles leads, so he holds, to artificial distinctions and to an unnatural subordination of one science to another.

Stumpf's first division is accordingly into the nature sciences, the mental sciences (Geisteswissenschaften), and the neutral sciences. This is a classification according to object (Gegenstand), and the object of a science is described as a conceptual form (Gebilde, p. $6 \mathrm{ff}$.). Even the individual, Stumpf points out, is described in conceptual terms. Such a conceptual form is, he adds (p. 9), posited as identical for all thinkers. ( 1 ) The nature sciences are distinguished, from this - the most fundamental - standpoint, in that their objects are 'the bearers ( Träger) - ordered in spatial-temporal relations - of regular changes, inferred from phenomena.' An emphasized feature of this conception ( $\mathrm{p} . \mathrm{I}_{3} \mathrm{ff}$.) is the teaching that mere phenomena are not the objects of the nature sciences. Color and the other specific qualities, and even sensible space, do not belong to the world of the physicist, who deals rather with purely mathematical formulæ and with their hypothesized 'bearers,' namely, 'a world of things existing independently of consciousness but related within itself according to causal laws.' (2) The objects of the mental sciences are the psychic functions as objects of thought, and their subjects, or ' bearers.' The main distinction within this second group of sciences is that between psychology, the science of the elemental psychic funcwith greater vigor. Cf. Stumpf's paper 'Zur Einteilung der Wissenschaften' for implicit admission of this doctrine by the teaching that psychology may discuss the 'subject' of the function. 
tions, and the sciences of the more complex social functions, for example, sociology and the science of religion. (3) Under the head of ' neutral sciences,' Stumpf next proceeds to define, on the one hand, metaphysics (the science of the connection of all objects, especially with reference to the criterion of reality, p. $42 \mathrm{ff}$.), and on the other hand, a group of allied sciences usually treated as aspects of either or both the nature sciences and the psychic sciences. These are (I) 'phenomenology,' or the science of phenomena-and, under this head, Stumpf would study all the sensible qualities, color, sound, warmth, and the like (p. $26 \mathrm{ff}$.), and ( 2 ) eidology, or the investigation of 'forms' - and here would fall the investigation, on the one hand, of logical concepts, and, on the other hand, of 'values' ( $p$. $3^{2}$ ); and finally (3) the study of relations.

It will be observed that Stumpf, although disclaiming a division on a single principle, has really brought all save two of the sciences under the headings of this division on the basis of conceptual object. These two, which he does not include in this classification, are, in the first place, history, which he describes as dealing primarily with individual and with fact, as opposed to law (p. 47 ff.) ; and, second, mathematics, defined (in one of the most valuable sections of the paper), as the science of the 'homogeneous' form conceptually gained, through abstractions and definitions, from the phenomenal (p. $7^{6}$, adapted). As thus defined, history is really, on Stumpf's principles, a mental science, and mathematics a branch of eidology; but Stumpf holds that this subordination minimizes the actual importance of these sciences and therefore, as has just been stated, he regards each as sui generis. Similarly, he distinguishes ethics, xsthetics, pedagogy, and the like as ' practical' in contrast with ' theoretical 'sciences, though he has already referred to them as branches of eidology. And finally, he defines philosophy with express intent to include within it all the sciences of the traditional faculty of philosophy.

This inadequate summary of a paper rich in suggestion has left many of its important features untouched. Mention must be made of the enumeration (p. $3^{8}$ ) of the problems of the doctrine of relations; of the careful distinction (p. 8I) of the a priori from the innate; and, most significant of all, of the very valuable discussion (p. 49 ff. and $80 \mathrm{ff}$.) of logical necessity. As I understand him, Stumpf conceives of logical necessity as the connectedness of concepts, learned with immediate assurance, by analytic attention; and he contrasts it with ' real necessity,' the connectedness of phenomena learned with assurance through repeated experience. 
An obvious criticism of Stumpf's classification has already been indicated. It is, after all, more logical than he is willing to admit, for all his sciences are, in the end, classified according to object. The most unessential of his main classes is that of the neutral sciences, since he attempts to coördinate phenomenology neither with eidology nor with the doctrine of relations - and still less with metaphysics. Indeed, he does not, in the opinion of the present writer, make good his exclusion of phenomenology from psychology. The other criticisms to be made concern Stumpf's fundamental teachings rather than this specific problem of the classification of the sciences: (I) The realism, prominent especially in his definition of the nature sciences, is nowhere argued, but is merely asserted, and is virtually yielded both by the admission that the world, supposed to be independent of consciousness, is an object of thought (ein Gedachtes), and by the conception of the object-independent-of-consciousness as in spatial and temporal relations. For 'spatial' and 'temporal,' as Stumpf has abundantly shown, are terms with a purely phenomenal significance and cannot be turned into extra-mental relations by an arbitrary act of hypothesis. Incidentally, it may be noted that the conception of 'bearer (Träger)' when it is not conceived as self, has no more validity - spite of Stumpf's disclaimer - than Locke's substance, an 'I know not what.' (2) In the second place, Stumpf's repeated assertions that psychology deals not only with psychic functions but with the subjects of these functions serves as a needed correction of Stumpf's own teaching in that it virtually identifies Funktionspsychologie with Ichpsychologie. For the subject of the psychic function can be none other than the conscious self, or I.

Mary Whiton Calkins.

WELIIESLEYY COLIEGE.

\section{EDUCATION.}

Motives, Ideals, and Values in Education. William Estabrook Chancellor. Boston, Houghton, Mifflin \& Co.

One would hardly expect the author of a series of arithmetics, and a volume like Our Schools, to produce such a book as the Motives, Ideals, and Values, which keeps as far away from the concrete work of teaching as it is possible to get. The book is really a philosophical and ethical reflection upon the fundamental bases of life, society, and education. Hardly anywhere throughout the entire five hundred closely printed pages is there a suggestion even of the practical interests and activities of the author; and it is difficult to conceive how 